\section{Military Technical College Kobry El-kobbah, Cairo, Egypt}

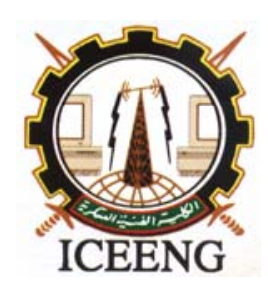

\author{
$5^{\text {th }}$ International Conference \\ on Electrical Engineering \\ ICEENG 2006
}

\title{
Electrical Breakdown at Sessile Water Droplets on Insulating Surfaces Subject to High AC Stress.
}

\author{
Dr. H. A. Gouda
}

\begin{abstract}
Electrical breakdown at the edges of sessile water droplets on a horizontal, insulating surface subject to high AC electrical stress has been studied experimentally. The behaviour of the water droplets under these conditions has been examined using a high-speed video camera and by detecting electrically partial discharge activity. Different modes of droplet vibration have been observed, some of which lead to transient changes in droplet contact angle at the insulator surface with concomitant changes in the electric field in the vicinity of the triple junction. These field effects have been calculated and their significance on partial electrical discharges discussed. Lateral spreading of water droplets has also been observed. It is considered this spreading is associated with the vibration and with the partial discharge activity.
\end{abstract}

\section{INTRODUCTION}

Surface pollution in the form of discrete water droplets is known to degrade the performance of high-voltage insulation. A water droplet plays a number of roles in the electrical breakdown at an air / insulator interference: it forms a stress enhancer because of its high permittivity; it deforms or may elongate under the influence of the electric field, through Coulomb and field-gradient forces, which can increase its stress-enhancing features; it can partly short out the insulating surface. Elongated droplets can coalesce to form a ribbon of water between the electrodes. The geometrical orientation and the hydrophilic or hydrophobic nature of an insulator surface can also affect the shape of a water droplet as can the presence of adhesive, cohesive and gravitation forces; crevices and ridges; pollution deposits; etc. See, for example $[1,2,3,4,5,6,7]$.

Surface hydrophobicity is one of the factors known to influence insulator performance. Contact angle, defined as the angle formed between the tangent to the water droplet surface and the horizontal surface in the region of the contact [7], is used to give a measure of the hydrophobic property of a surface. During service conditions hydrophobicity may be lost, and insulator surface may become hydrophilic. It is known that hydrophilic surfaces have a poor performance under wet condition [8].

\footnotetext{
* Electrical Power and Energy Department, MTC, Cairo, Egypt.
} 
The present paper describes an experimental study of electrical breakdown at the edges of sessile water droplets on a PE surface subject to AC electrical stress up to a maximum of $20 \mathrm{kV} / \mathrm{cm}(\mathrm{RMS})$ at $50 \mathrm{~Hz}$. The study involves observing the vibration and other motion of discrete water droplets using a high-speed video camera operating at 3000 frames per second whilst electrically detecting any partial discharge activity in the vicinity of the droplets. The significance of the droplet vibration on electrical stress enhancement is investigated along with the effects on partial discharge activity. Lateral spreading of the water droplets is considered to be evidence of changes in the hydrophobic properties of the insulator surface brought about by the partial discharge activity.

\section{EXPERIMENTAL PROCEDURE}

Figure 1 illustrates the general experimental arrangement used to investigate the behaviour of discrete water droplets on a polyethylene surface under AC stress.

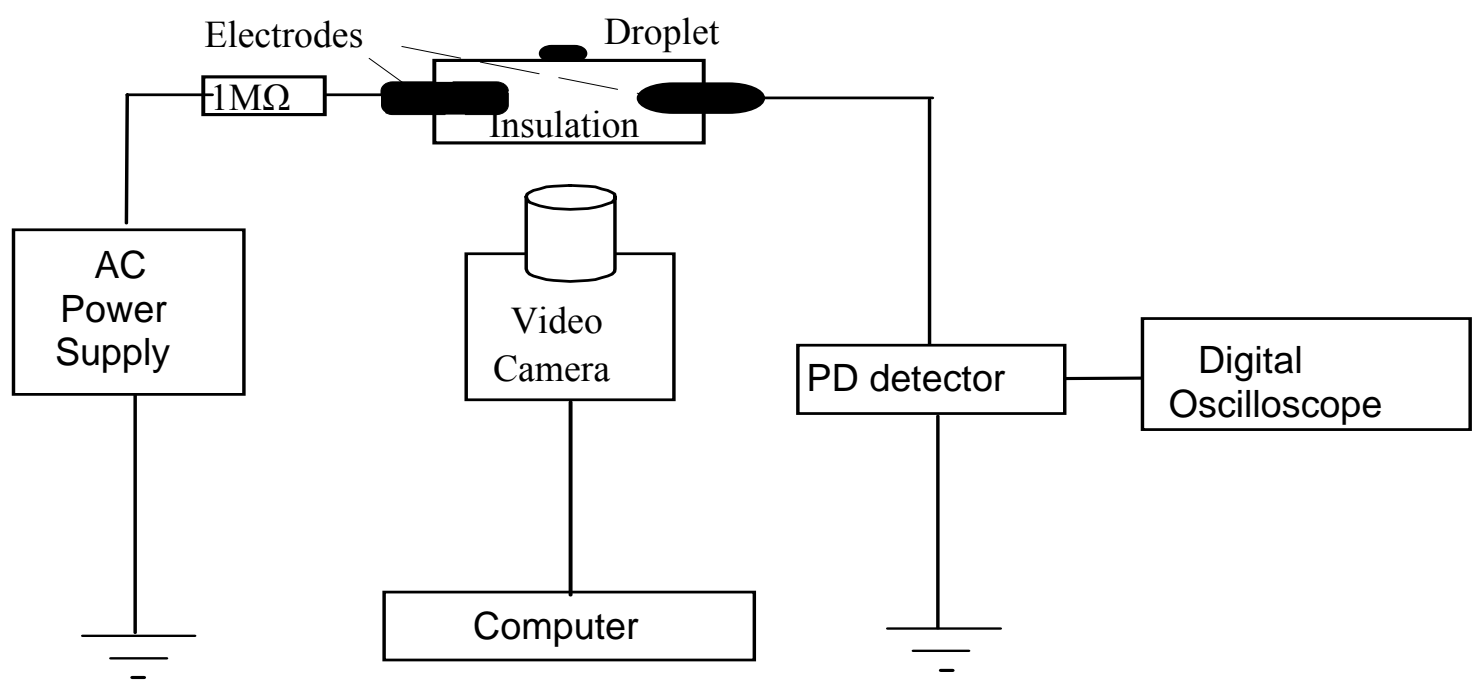

Figure 1. Schematic representation of the experimental arrangement.

The high voltage electrode was raised to a maximum of $20 \mathrm{kV} \mathrm{AC}, 50 \mathrm{~Hz}$. The second electrode was effectively grounded through a low-value resistor used to allow the detection of partial discharges. The electrode arrangement allowed a high electrical field to be generated along the surface of the PE sample. This field was computed using a finite element program. The camera was interfaced to a computer, which captured the camera output and subsequently stored the data on CDROM. With the present arrangement, good images were obtained up to a maximum of 3000 frames per second. The volume of the water droplet was typically $10 \mu 1$ and was placed on the PE surface using a syringe. For these initial studies, tap water was used with a conductivity of up approximately $100 \mu \mathrm{s} / \mathrm{cm}$.

Typically, the applied voltage was raised slowly until PD activity was detected. The level of PD activity was then monitored and recorded using the digital oscilloscope. The video camera was then used to detect the onset of vibration of the water drop and the vibration pattern was recorded. The applied stress was then raised until partial discharge activity 
around the droplet became visible. This activity was also recorded using the high-speed camera.

\section{RESULTS AND DISCUSSION}

3.1 Electrical detection of partial discharges. Figures 2, to 5 show the partial discharge (PD) activity detected electrically by placing a $100-\Omega$ resistor in series with the test gap and observing the voltage pulses generated across it with a digital Oscilloscope.

Fig. (2) Partial Discharge no Water Droplet

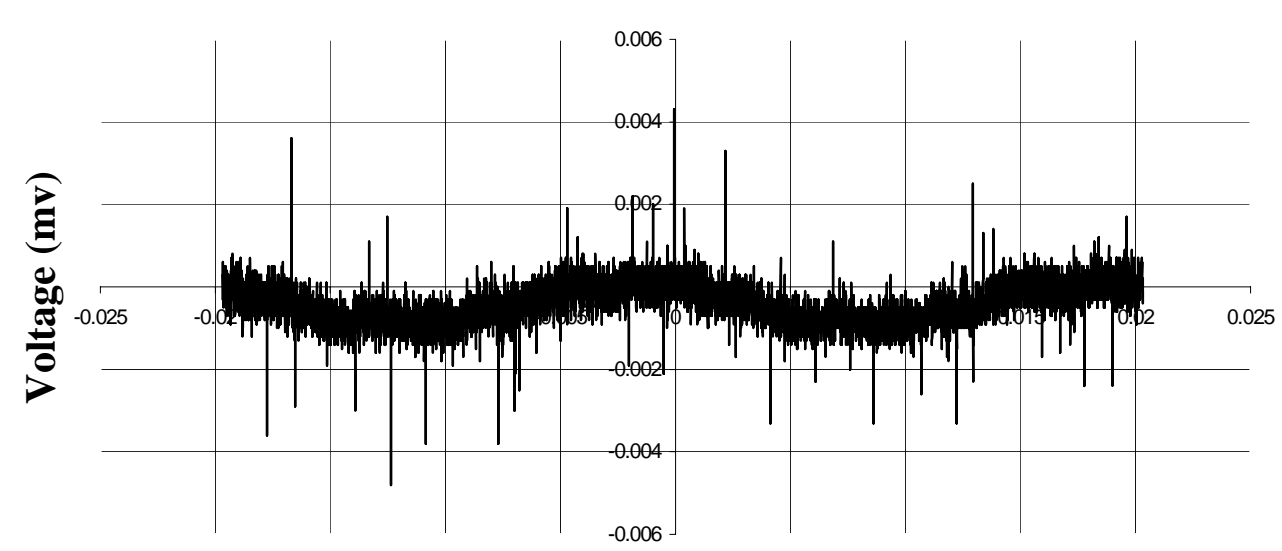

Time (4ms)

Fig. (3) Partial Discharge with water droplet over the sample

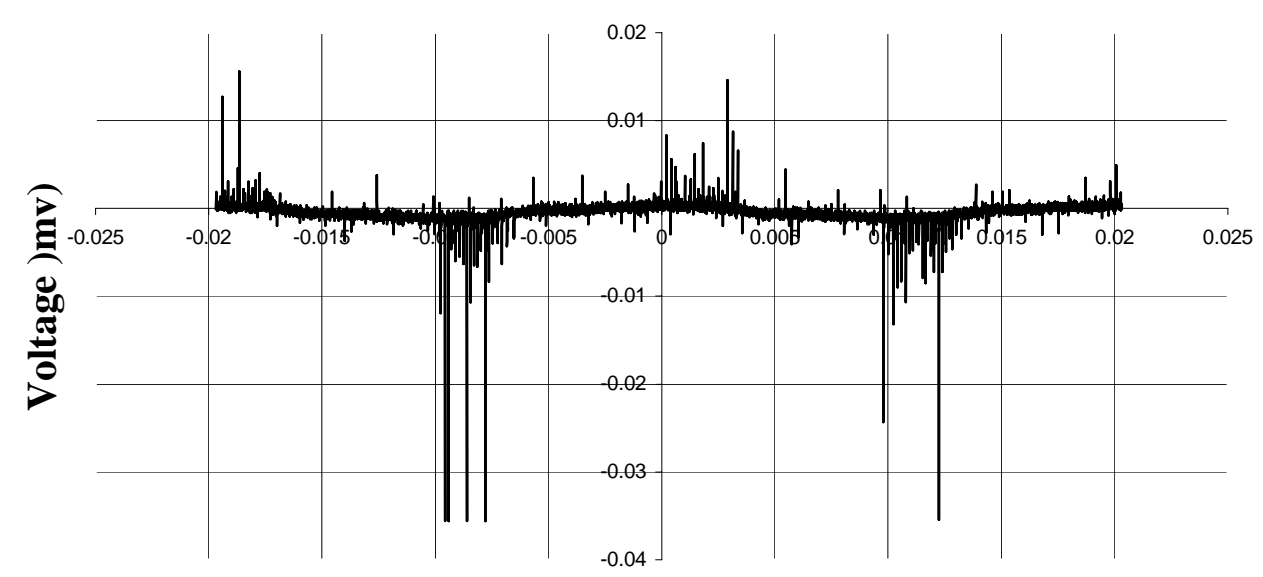

Time (4ms) 
Fig (4) The Partial Discharge with the Water Droplet scattered over the sample

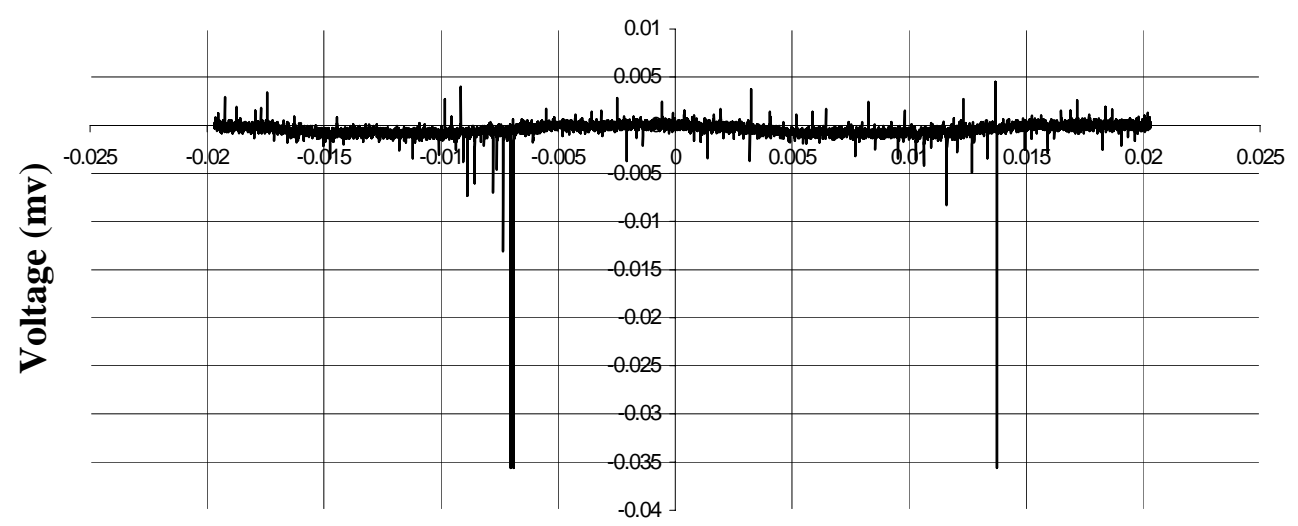

Time (4ms)

Fig. (5) Break Down when the Water Droplet expanded

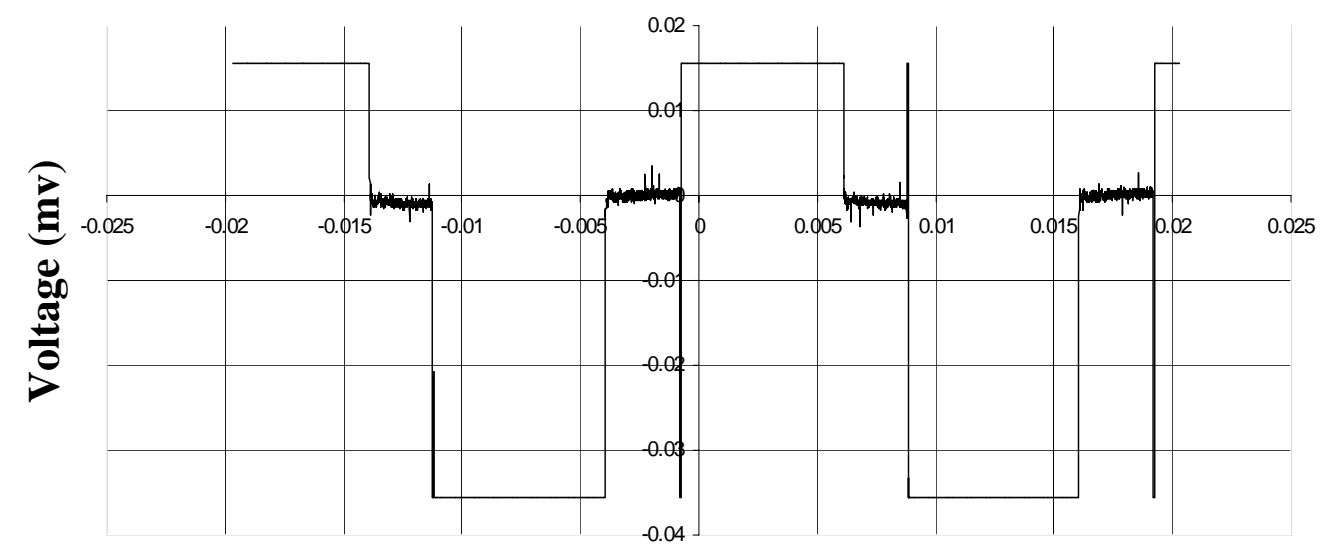

Time (4ms)

Figure 2 shows that, when no water droplet was present on the sample surface, the onset of PD activity was detected at about $9.5 \mathrm{kV}$. This PD activity occurs during both half cycles close to the peak value of the applied voltage. At this level of applied voltage, the PD activity was not strong enough to generate any visual damage to the sample or to lead to full breakdown, at least in the short term. In Figure 3, it is shown that when a water droplet is located at the centre of the test sample between the two electrodes, PD activity could be detected when the applied voltage was typically around $6.0 \mathrm{kV}$. However, at this level of stress no vibration or motion of the droplet was observed. Partial discharges over the negative half cycle appear stronger than during the positive half cycle. These PD signals were used as a triggering signal for the high-speed digital camera. Figure 4 shows the level of PD activity when the voltage was increased to $7 \mathrm{kV}$. At this level of applied field, the water droplet was observed to vibrate and subsequently spread over the surface of the insulation sample. Again, the PD activity recorded during the negative half cycle is higher. Figure 5 shows the PD activity when the applied voltage is increased to $8.5 \mathrm{kV}$. In this case, vibration 
of the water droplet lead to a spreading over the sample until contact was made with one, or both electrodes, resulting in breakdown of the test sample with physical damage to its surface.

3.2 Observation of droplet motion. During the above electrical measurements of partial discharge activity, the mechanical activity undergone by the water droplets on the insulation surface was recorded using a high-speed digital video camera operating at up to 3000 frames per second. Figure 6 shows a sessile water droplet on the insulation surface under an applied voltage of $7 \mathrm{kV}$ at $50 \mathrm{~Hz}$.

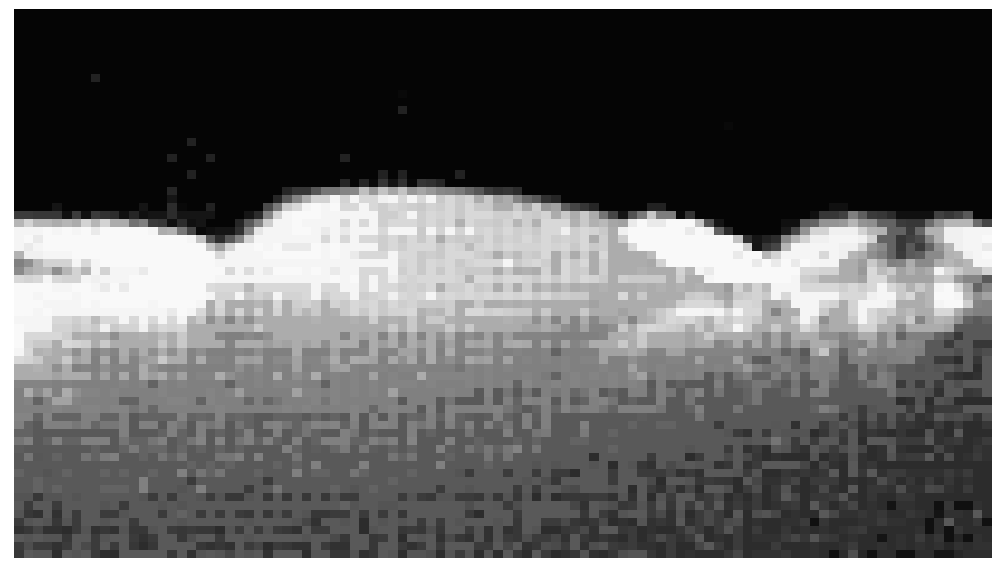

Figure 6. Droplet on insulation surface. Average applied stress 7kV/cm (RMS).

From the video camera records, vibration of the droplet was evident, as were partial discharges at the edges of the droplet nearest to the electrodes.

3.3 Electric field at the Edge of a water droplet. The electric field around a droplet on a flat insulating surface was computed in order to examine how electrical breakdown of the air surrounding the droplet might occur around the water droplet edge, as indicated in some of the digital camera records. Figure 7 shows the configuration of droplet examined in this way.

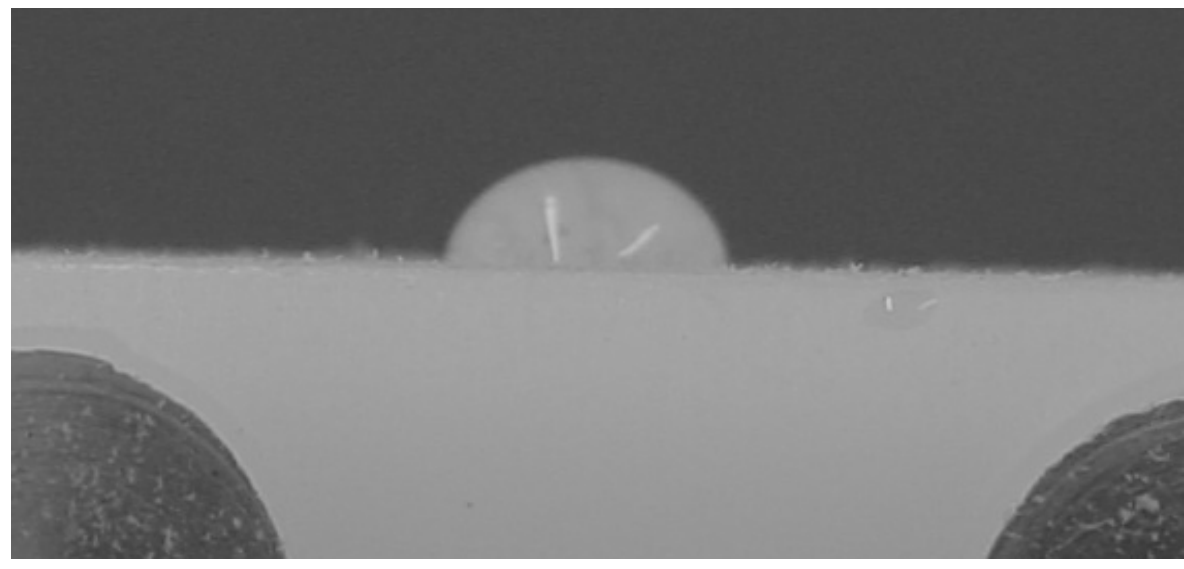

Figure 7. Sessile water droplet on a horizontal PE surface

To examine this, the field along the polymer surface $\left(\mathrm{E}_{\mathrm{s}}\right)$ starting at the triple junction was compared with the field along a field line $\left(\mathrm{E}_{\mathrm{l}}\right)$ starting on the droplet surface, but at a short 
distance away from the triple junction. Figure 8 shows the ratio of $E_{1}$ to $E_{s}$ as a function of distance from the droplet.

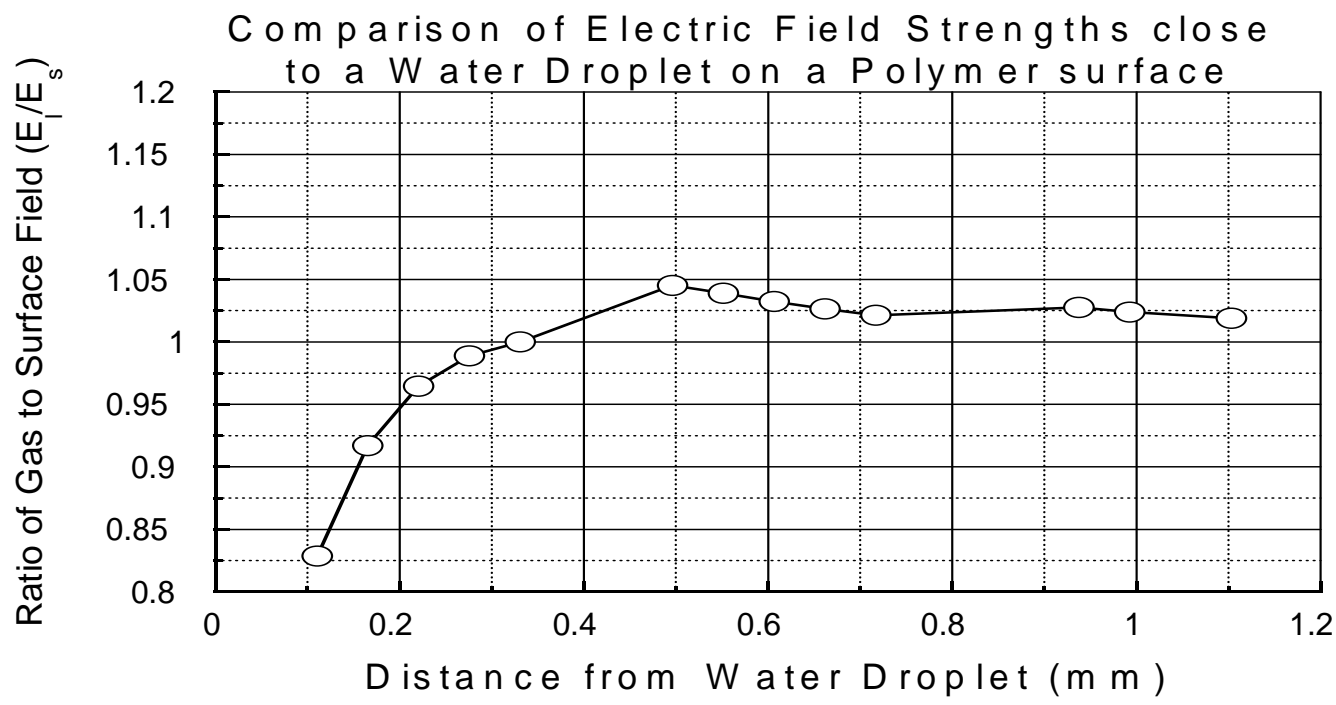

Figure 8. The ratio of $E_{1}$ to $E_{s}$ as a function of distance from droplet surface.

This shows that, for the droplet examined and at locations away from the droplet surface, $\mathrm{E}_{1}$ can exceed $E_{s}$. This suggests it may be possible to preferentially satisfy the conditions for electrical breakdown in the surrounding air at some distance away from the triple junction, as indicated by digital camera records. Further examination of this possibility is to be undertaken.

\section{CONCLUSIONS.}

For the conditions examined. With increasing applied AC stress, partial discharges precede the onset of droplet vibration. Lateral spreading of the droplet in the direction of the applied field follows the onset of vibration. There is evidence of partial discharge activity not associated with the triple junction and that, at the same locations, the electric field in the gas surrounding the droplet can exceed the field on the supporting surface.

\section{REFERENCES}

[1] - N. Dhahbi-Megriche and A. Boreal,' Flashover Dynamic Model of Polluted Insulators under ac Voltage', IEEE Trans. on Dielectric and Elec. Insult. Vol.7 No.2 April 2000.

[2] - S. Shihab and L. Zhou,' Simulation of Contamination Performance of Outdoor High Voltage Insulators,' IEEE/KTH Stockholm Power Tech Conference, Stockholm, Sweden, June 18-22, 1995.

[3] - S. Chakravorti and P. K. Mukherjee,' Power Frequency and Impulse Field Calculation around a HV Insulator with Uniform and Nonuniform Surface Pollution,' IEEE Trans. on Elec. Insult. Vol.28 No.1 February 1993.

[4] - D A Swift,' Flashover of an Insulator Surface in Air Due to polluted Water Droplets,' Proceeding of the $4^{\text {th }}$ International Conference on Properties Applications of Dielectric Materials July 3-8, 1994, Brisbane Australia.

[5] - S. M. Ghufran Ali and H. M. Ryan,' Insulation Co - ordination under polluted conditions,' the $7^{\text {th }}$ BEAMA International Electrical Insulation Conference. 
[6] - B. H. Crichton and H. A. Gouda,' A Study of Water Droplet Behavior on Insulation Surface under High Electric stress,' UPEC 2001 Swansea University Wales.

[7] - T. Tokoro and R. Hackam,' Loss and Recovery of Hydrophobicity and Surface Energy of HTV Silicone Rubber,' IEEE Trans. on Dielectric and Elec. Insult. Vol.8 No.6 Dec. 2001.

[8] - Ivan J. S. Lopes, Shesha H. Jayaram and Edward A. Cherney,' A Study of Partial Discharges from Water Droplets on a Silicone Rubber Insulating,' IEEE Trans. on Dielectric and Elec. Insult. Vol.8 No.2 April 2001. 